\title{
An Italian cost-effectiveness analysis of paclitaxel albumin (nab-paclitaxel) versus conventional paclitaxel for metastatic breast cancer patients: the COSTANza study
}

\author{
This article was published in the following Dove Press journal: \\ ClinicoEconomics and Outcomes Research \\ 9 April 2013 \\ Number of times this article has been viewed
}

\author{
Carlo Lazzaro' \\ Roberto Bordonaro ${ }^{2}$ \\ Francesco Cognetti ${ }^{3}$ \\ Alessandra $\mathrm{Fabi}^{3}$ \\ Sabino De Placido 4 \\ Grazia Arpino ${ }^{4}$ \\ Paolo Marchetti ${ }^{5}$ \\ Andrea Botticelli ${ }^{5}$ \\ Paolo Pronzato 6 \\ Elisa Martelli ${ }^{7}$ \\ 'Studio di Economia Sanitaria, Milan, \\ Italy; ${ }^{2}$ Public Hospital Trust Garibaldi, \\ Catania, Italy; ${ }^{3}$ Istituto dei Tumori \\ Regina Elena, Rome, Italy; ${ }^{4}$ School \\ of Medicine, Federico II University, \\ Naples, Italy; ${ }^{5}$ Department of Medical \\ Oncology, School of Medicine, \\ Sapienza University Hospital, \\ Rome, Italy; ${ }^{6}$ Istituto di Ricovero \\ e Cura a Carattere Scientifico, \\ Azienda Ospedaliera Universitaria \\ San Martino - Istituto Scientifico \\ Tumori, Istituto Nazionale per la \\ Ricerca sul Cancro, Genoa, Italy; \\ ${ }^{7}$ Health Economics and Outcomes \\ Research, Celgene Srl, Milan, Italy
}

Correspondence: Carlo Lazzaro Studio di Economia Sanitaria, 19 Via Stefanardo da Vimercate, Milan I-20 I28, Italy

Tel +3902 26000516

Email carlo.lazzaro@tiscalinet.it
Purpose: Paclitaxel albumin (nab-paclitaxel) is a nanoparticle albumin-bound paclitaxel formulation aimed at increasing therapeutic index in metastatic breast cancer. When compared to conventional paclitaxel, nab-paclitaxel has a reported longer time to progression, higher response, lower incidence of neutropenia, no need for premedication, shorter time of administration, and in pretreated metastatic breast cancer patients, extended overall survival. This study investigates the cost-effectiveness of nab-paclitaxel versus conventional paclitaxel for pretreated metastatic breast cancer patients in Italy.

Materials and methods: A Markov model with progression-free, progressed, and dead states was developed to estimate costs, outcomes, and quality adjusted life years over 5 years from the Italian National Health Service viewpoint. Patients were assumed to receive nab-paclitaxel $260 \mathrm{mg} / \mathrm{m}^{2}$ three times weekly or conventional paclitaxel $175 \mathrm{mg} / \mathrm{m}^{2}$ three times weekly. Data on health care resource consumption was collected from a convenience sample of five Italian centers. Resources were valued at Euro $(€)$ 2011. Published utility weights were applied to health states to estimate the impact of response, disease progression, and adverse events on quality adjusted life years. Three sensitivity analyses tested the robustness of the base case incremental cost-effectiveness ratio (ICER).

Results and conclusion: Compared to conventional paclitaxel, nab-paclitaxel gains an extra 0.165 quality adjusted life years ( 0.265 life years saved) and incurs additional costs of $€ 2506$ per patient treated. This translates to an ICER of $€ 15,189$ (95\% confidence interval: $€ 11,891-€ 28,415)$. One-way sensitivity analysis underscores that ICER for nab-paclitaxel remains stable despite varying taxanes cost. Threshold analysis shows that ICER for nab-paclitaxel exceeds $€ 40,000$ only if cost per mg of conventional paclitaxel is set to zero. Probabilistic sensitivity analysis highlights that nab-paclitaxel has a 0.99 probability to be cost-effective for a threshold value of $€ 40,000$ and is the optimal alternative from a threshold value of $€ 16,316$ onwards. Based on these findings, nab-paclitaxel can be considered highly cost-effective when compared to the acceptability range for ICER proposed by the Italian Health Economics Association (€25,000-€40,000).

Keywords: metastatic breast cancer, nab-paclitaxel, conventional paclitaxel, cost-effectiveness analysis, Italy

\section{Introduction}

According to the most recent epidemiological data, incidence and prevalence of breast cancer in Italy are reported to be 78.4 and 686.2 cases per 100,000 inhabitants per year. ${ }^{1,2}$ Taxanes (paclitaxel and docetaxel) play major roles for treating metastatic 
breast cancer (MBC). ${ }^{3,4}$ Paclitaxel albumin (nab-paclitaxel; Abraxane ${ }^{\circledR}$; Celgene Corporation, Summit, NJ, USA) is the first of a new class of anticancer agents that incorporates nanoparticle albumin bound (nab) technology. Nab technology has been developed to obtain solvent free formulations of hydrophobic cytotoxic drugs. ${ }^{5}$

Research has also suggested that the albumin component improves the localization of cytotoxics to the tumor site. ${ }^{5-7}$ However, the formulation of taxanes requires the inclusion of solvent and surfactant excipients that have been associated with dose limiting adverse events (AEs), such as acute hypersensitivity reactions and peripheral neuropathy. ${ }^{8-10}$

$\mathrm{Nab}$-paclitaxel was developed with the aim of increasing therapeutic index in MBC and has been recognized as an important treatment option for this disease. ${ }^{3,4}$ An international, randomized, open-label, Phase III study was performed at 70 sites (28 Russia/Ukraine sites, 350 patients; 22 United States/Canada sites, 37 patients; and 20 United Kingdom sites, 67 patients) to confirm preclinical studies demonstrating superior efficacy and reduced toxicity of nab-paclitaxel compared with conventional paclitaxel. ${ }^{11}$ Patients were randomly assigned to 3-week cycles of either nab-paclitaxel $260 \mathrm{mg} / \mathrm{m}^{2}$ intravenously (IV) without premedication (132 out of 229 overall patients received nab-paclitaxel as second line or greater therapy) or conventional paclitaxel $175 \mathrm{mg} / \mathrm{m}^{2} \mathrm{IV}$ with premedication (136 out of 225 overall patients received conventional paclitaxel as second-line or greater therapy). Most women in second-line or greater therapy had previously received anthracycline therapy (77\%), and none had prior exposure to taxanes for MBC.

Nab-paclitaxel demonstrated significantly higher response rates compared to conventional paclitaxel for all patients (33\% versus $19 \%$, respectively; $P=0.001$ ) and for those who were pretreated as well (27\% versus $13 \%$, respectively; $P=0.006)$. Nab-paclitaxel reported significantly longer time to progression (TTP) versus conventional paclitaxel for all patients (23.0 versus 16.9 weeks, respectively; hazard ratio $[\mathrm{HR}]=0.75 ; P=0.006)$ and for those who received the study drug as a second-line or greater therapy (20.9 versus 16.1 weeks, respectively; $\mathrm{HR}=0.73 ; P=0.020$ ). In pretreated patients who received nab-paclitaxel instead of conventional paclitaxel, the difference in overall survival (OS) was statistically significant (56.4 versus 46.7 weeks, respectively; HR $=0.73 ; P=0.024)$. At the time of the analyses (October 2004), the median censoring time for overall patient survival was 103 weeks for the nab-paclitaxel group and 101 weeks for the conventional paclitaxel group.
The incidence of grade 4 neutropenia was significantly lower for nab-paclitaxel versus conventional paclitaxel (9\% versus $22 \%$, respectively; $P=0.001$ ) despite a $49 \%$ higher paclitaxel dose. Also, despite the absence of premedication and shorter time of administration, no hypersensitivity reactions occurred with nab-paclitaxel.

In 2008, on the basis of improved response and extended OS in the pretreated subgroup of patients, ${ }^{11}$ nab-paclitaxel received a marketing authorization from the European Medicines Agency for the treatment of MBC in adult patients who have failed first-line treatment and for whom standard, anthracycline-containing therapy is not indicated. ${ }^{12,13}$

The aim of the COST-effectiveness Analysis of Nabpaclitaxel (COSTANza, a feminine name in Italian) study was to perform a model-based cost-effectiveness analysis of IV nab-paclitaxel $260 \mathrm{mg} / \mathrm{m}^{2},{ }^{14,15}$ three times weekly (the approved schedule for second-line MBC treatment), ${ }^{16}$ versus conventional IV paclitaxel $175 \mathrm{mg} / \mathrm{m}^{2}$ three times weekly monotherapy regimens in $\mathrm{MBC}$ patients as a second-line treatment whenever standard, anthracycline-containing therapy is not indicated. ${ }^{13}$

\section{Materials and methods Patients and treatment}

Baseline characteristics of patients included in the economic evaluation were assumed to match those of patients included in the abovementioned randomized controlled trial (RCT) aimed at comparing nab-paclitaxel versus conventional paclitaxel in patients with MBC. ${ }^{11}$ Patients were assumed to have a body surface area of $1.70 \mathrm{~m}^{2}$.

\section{State-transition model}

A spreadsheet supported, 5-year (87 cycles), three-state (progression free, progressed, and death) Markov model ${ }^{14,17}$ was developed in Microsoft Excel ${ }^{\circledR} 2003$ (version 11, Microsoft Corporation, Redmond, WA, USA) to compare cost and quality adjusted life years (QALYs) of nab-paclitaxel versus conventional paclitaxel.

A 5-year period lifetime horizon for MBC patients was chosen as it was considered appropriate by foreign institutional advisory bodies who issued recommendations for the use of nab-paclitaxel for the same indication. ${ }^{18,19}$ Transition probabilities among Markov model states were estimated via the Weibull distribution. The Weibull distribution was used to generalize progression-free survival (PFS) and OS, in order to extrapolate survival in the model beyond the follow-up of the abovementioned RCT that compared nabpaclitaxel versus conventional paclitaxel. ${ }^{11}$ From the same 
RCT the incidence of grade 3 and 4 AEs for nab-paclitaxel and conventional paclitaxel was obtained (Table 1). The model assumes all AEs occurred during the first cycle of chemotherapy only.

\section{Effectiveness, utility, and QALYs}

Effectiveness outcomes for nab-paclitaxel and conventional paclitaxel included response in nonprogressed patients, TTP, and OS. ${ }^{11}$

Utility is indicative of patients' preferences over different health states. Utility is bounded between zero (ie, death or health state considered worse than death) and one (ie, perfect health) regardless the disease under evaluation. ${ }^{14,15}$ Utilities representing health-related quality of life for each state included in the Markov model (stable disease: 0.65; responder: 0.81 ; progression: 0.45 ; death: 0) were drawn from a pooled analysis of MBC utility weights. ${ }^{20}$ Utility decrements due to the occurrence of AEs such as febrile neutropenia or infection $(-0.21)$, or nonspecific toxicity in responders $(-0.14)$ and patients with stable disease $(-0.11)$ were also considered. ${ }^{20}$

QALYs calculation consisted in multiplying patients' years of life saved for the utility related to each health state. QALYs were then aggregated across the 5-year time horizon assumed in the Markov model.

\section{Resource consumption and associated costs}

As cost-effectiveness analysis was performed following the Italian National Health Service (INHS) viewpoint, only health care resources provided by INHS were identified, quantified, and costed. Health care resources included drugs, personnel time, outpatient services, and hospitalization

Table I Comparison of grade 3 and 4 adverse events: relative frequencies

\begin{tabular}{lll}
\hline Adverse event & Nab-paclitaxel & $\begin{array}{l}\text { Conventional } \\
\text { paclitaxel }\end{array}$ \\
\hline Neutropenia & $30.57 \%$ & $46.22 \%$ \\
Febrile neutropenia & $1.75 \%$ & $0.89 \%$ \\
Infection & $4.80 \%$ & $3.11 \%$ \\
Anemia & $0.87 \%$ & $0.44 \%$ \\
Diarrhea & $0.44 \%$ & $1.33 \%$ \\
Nausea & $3.49 \%$ & $0.44 \%$ \\
Nervous system & $11.35 \%$ & $2.67 \%$ \\
Pain (included ararthralgia) & $14.85 \%$ & $6.22 \%$ \\
Asthenia & $8.30 \%$ & $3.11 \%$ \\
Myalgia & $7.42 \%$ & $1.78 \%$ \\
Vomiting & $3.93 \%$ & $1.33 \%$ \\
Stomatitis & $1.75 \%$ & $0.44 \%$ \\
\hline
\end{tabular}

related to chemotherapy as well as AEs management. Part of health care resource consumption was collected from a convenience sample of five Italian oncological centers at the forefront in MBC treatment between June and July 2011. ${ }^{21}$

An ad hoc, spreadsheet-supported questionnaire aimed at collecting health care resource consumption for premedication, chemotherapy, administration, postmedication, and AEs management (drugs; clinical investigations, oncologist and specialist visits provided in an outpatient setting; inpatient admissions and day hospitals [DH]), as well as nurses' and physicians' time for chemotherapy preparation, administration, and patients' surveillance in outpatient, $\mathrm{DH}$, and inward settings, was sent to the five participating oncological centers to be filled out by a senior oncologist. After all questionnaires were returned and completed (end of summer 2011), one follow-up phone call, which aimed at obtaining some clarifications on the answers given, took place with all five senior oncologists. If necessary, the answers were modified on the basis of the discussion with the clinicians.

Health care resource consumption was obtained from published sources for end of life care, ${ }^{22}$ and estimated on the grounds of few research hypotheses for supportive care and patients' assessment. All costs were expressed in Euro $(€)$, year 2011 values.

Costs for drugs, patients' surveillance, assessment and support, best supportive care following progression, end of life care, clinical and diagnostic tests, oncologist and specialist visits, transfusions, and hospitalizations were obtained from published sources (Table 2). ${ }^{22-29}$ Since they are administered in health care facilities, nab-paclitaxel and generic conventional paclitaxel were valued at ex factory price, which is around $33 \%$ off consumer price, whereas other drugs were valued at consumer price. The costs of drugs and health care services administered during hospitalization were considered included in the daily full cost of the hospital stay.

Physicians' and nurses' time for preparing and administering taxanes, as well as for patients' surveillance, were determined on a per minute basis considering the average duration of a $\mathrm{DH}$ chemotherapy session for $\mathrm{MBC}$ patients in Italy (240 minutes). ${ }^{27}$ Each minute was then valued by dividing the INHS Diagnosis Related Group (DRG) tariff (code $410)$ for chemotherapy performed in DH setting (€427.76) by 240 minutes (€1.78). ${ }^{29}$ In order to avoid double counting (ie, costing the same resource twice), ${ }^{15}$ the cost of nab-paclitaxel and conventional paclitaxel, which was already calculated separately, and the cost per minute was eventually halved 
Table 2 Unit costs $(€ 20 \mathrm{II})$

\begin{tabular}{|c|c|c|c|}
\hline Cost item (mean \pm SD) & Nab-paclitaxel & Conventional paclitaxel & Source \\
\hline \multicolumn{4}{|l|}{ Chemotherapy cycle } \\
\hline Taxanes $^{\mathrm{a}}$ & $1063.70(-)^{\mathrm{b}}$ & $8 \mid 4.77(-)$ & 23,24 \\
\hline Premedication & $0.45( \pm 0.90)$ & $9.22( \pm 5.29)$ & 25,26 \\
\hline $\begin{array}{l}\text { Preparation, administration and patient } \\
\text { surveillance - physicians' and nurses' time }\end{array}$ & $62.38( \pm 15.86)$ & $150.96( \pm 68.55)$ & 27,29 \\
\hline Administration - drugs others than taxanes ${ }^{c}$ & $16.79( \pm 22.38)$ & $10.50( \pm 7.66)$ & 25,26 \\
\hline Postmedication & $5.19( \pm 10.38)$ & $10.75( \pm 12.48)$ & 25,26 \\
\hline $\begin{array}{l}\text { Assessment and support - patients } \\
\text { receiving chemotherapy }\end{array}$ & \multicolumn{2}{|c|}{$203.85(-)$} & 22,28 \\
\hline Assessment and support - patients off treatment & \multicolumn{2}{|c|}{$150.8 \mid(-)$} & 22,28 \\
\hline Best supportive care following progression & \multicolumn{2}{|c|}{$344.77(-)$} & 22,28 \\
\hline End of life care & \multicolumn{2}{|c|}{$1193.00(-)$} & 22,28 \\
\hline \multicolumn{4}{|l|}{ Grade 3 and 4 adverse events } \\
\hline Anemia & \multicolumn{2}{|c|}{$3061.86( \pm 1655.70)$} & $25,26,28,29$ \\
\hline Asthenia & \multicolumn{2}{|c|}{$133.26( \pm 230.27)$} & $25,26,28,29$ \\
\hline Diarrhea & \multicolumn{2}{|c|}{$196.08( \pm 354.48)$} & $25,26,28,29$ \\
\hline Febrile neutropenia & \multicolumn{2}{|c|}{$2387.75( \pm 1975.89)$} & $25,26,28,29$ \\
\hline Infection & \multicolumn{2}{|c|}{$463.45( \pm 282.21)$} & $25,26,28,29$ \\
\hline Myalgia & \multicolumn{2}{|c|}{$30.51( \pm 42.15)$} & $25,26,28,29$ \\
\hline Nausea & \multicolumn{2}{|c|}{$52.17( \pm 52.26)$} & $25,26,28,29$ \\
\hline Nervous system & \multicolumn{2}{|c|}{$79.78( \pm 66.03)$} & $25,26,28,29$ \\
\hline Neutropenia & \multicolumn{2}{|c|}{$1245.89( \pm 620.46)$} & $25,26,28,29$ \\
\hline Pain (included arthralgia) & \multicolumn{2}{|c|}{$36.38( \pm 50.76)$} & $25,26,28,29$ \\
\hline Stomatitis & \multicolumn{2}{|c|}{$585.00( \pm 772.98)$} & $25,26,28,29$ \\
\hline Vomiting & \multicolumn{2}{|c|}{$212.27( \pm 369.34)$} & $25,26,28,29$ \\
\hline
\end{tabular}

Notes: ${ }^{a}$ Cost per $\mathrm{mg}$ : nab-paclitaxel $=€ 2.45$; conventional paclitaxel $=€ 2.80$; ${ }^{\text {b when }}$ cost estimate was based upon research hypotheses, no SD was calculated; cantiemetics.

Abbreviation: SD, standard deviation.

(€0.89). This procedure was probably quite conservative, as drugs for chemotherapy can well absorb up to $80 \%$ of DRG $410 \mathrm{DH}$ tariff in Italy. ${ }^{30}$

The mean cost for each AE was calculated by weighting its unit cost for the relative frequency in nab-paclitaxel and conventional paclitaxel patients (Tables 1 and 2). ${ }^{11}$

As recommended by reference literature and Italian guidelines on the economic evaluation of health care programs, costs and QALYs were discounted on a 3-week basis using a $3 \%$ annual real social rate..$^{14,15,31}$

\section{Cost-effectiveness analysis}

Cost-effectiveness analysis is aimed at calculating the ratio of the difference in terms of both costs (incremental cost or $\Delta \mathrm{C}$ ) and QALYs (incremental QALYs or $\triangle$ QALYs) between alternative health care programs (ie, nab-paclitaxel versus conventional paclitaxel). ${ }^{14,15}$

The ratio of incremental cost to incremental QALYs (ie, $\left.\left[\operatorname{Cost}_{\mathrm{A}}-\operatorname{Cost}_{\mathrm{B}}\right] /\left[\mathrm{QALYs} \mathrm{A}_{\mathrm{A}}-\mathrm{QALYs}_{\mathrm{B}}\right]\right)$ is named the incremental cost-effectiveness ratio (ICER; ie, $\Delta \mathrm{C} / \Delta \mathrm{QALYs}$ ). ${ }^{14,15}$ In general, ICER means the cost of obtaining an incremental effectiveness unit (eg, an incremental QALY) by adopting the health care program that is more costly and more effective than the comparator(s).

\section{Statistical analysis}

Relative AE frequencies are reported (Table 1). Point estimate and the $95 \%$ confidence interval $(95 \% \mathrm{CI})$ were determined for hazard ratios (HR), odds ratios (OR), relative risk (RR), and risk differences (RD). Statistical significance was reached whenever the $95 \% \mathrm{CI}$ did not contain the null value (ie, 1 for HR, OR, and RR; 0 for RD) ${ }^{32}$

Unless otherwise stated, resource volume and unit costs for premedication, chemotherapy preparation, and administration, as well as patients' surveillance, postmedication, and AEs management, were calculated on the grounds of the information provided by the five oncological centers participating at this research project, and were reported as the mean ( \pm standard deviation).

Utility weights and unit 5-year costs for chemotherapy cycle with taxanes, patients' assessment and support, best supportive care following progression, and end of life care 
were reported as point estimates only, as no assumption about their dispersion around the mean was made in the base case analysis. No hypothesis test was performed.

\section{Sensitivity analyses}

Sensitivity analysis allows for uncertainty in the economic evaluation of health care programs. ${ }^{15}$ Three different sensitivity analyses tested the robustness of the base case results.

A one-way sensitivity analysis, in which variables are changed one at time while keeping the other ones at their baseline levels, ${ }^{14,15,33}$ was carried out on: RR for response to therapy; HR for TTP and OS; cost of both taxanes; AEs with the highest and the lowest mean unit cost for their management (anemia and myalgia, respectively); reduction in DRG 410 DH tariff of $0 \%$ (ie, assuming that the whole cost of taxanes is funded by INHS outside the DRG tariff) and $80 \%$ (ie, the highest expected share of DRG $410 \mathrm{DH}$ tariff consumed by drugs for chemotherapy) ${ }^{30}$ utility values for: stable disease, stable responders and disease progression; real social discount rate $(0 \%, 5 \%, 7 \%, 10 \%)$, that usually plays a relevant role as health care programs stretch over time. ${ }^{14}$

As far as the RR for response to therapy, HR for TTP, and OS are concerned, the base case estimate was replaced with the lower and the upper limit of the $95 \%$ CI.

For the remaining variables included in the one-way sensitivity analysis other than real social discount rate and DRG 410 DH tariff, a $\pm 10 \%$ variation of the base case value was applied, consistently with the approach followed in a previous economic evaluation on lung cancer carried out in Italy. ${ }^{34}$ The impact of the duration of the Markov model on ICER was also considered.

In a threshold analysis, the base case cost per mg of conventional paclitaxel was reduced until nab-paclitaxel was no more cost-effective. A probabilistic sensitivity analysis took into account the uncertainty surrounding the base case ICER estimate via a 1000-iteration Monte Carlo simulation. ${ }^{14,15,33,35,36}$

The percentile method was used to calculate the $95 \%$ CI for the ICER by picking the 26th and the 975th iterations of the Monte Carlo simulation. ${ }^{35-39}$ In addition, the cost-effectiveness of nab-paclitaxel versus conventional paclitaxel was further explored via a cost-effectiveness acceptability curve (CEAC) and a cost-effectiveness acceptability frontier (CEAF).

On the grounds of available evidence, ${ }^{40} \mathrm{CEAC}$ reports the probability for nab-paclitaxel to be cost-effective over a range of different threshold values per QALY gained, ${ }^{15,41,42}$ whereas $\mathrm{CEAF},{ }^{36,41}$ constructed by exploiting an algebraic manipulation of the ICER named net monetary benefit, ${ }^{36,41-44}$ highlights from which threshold value onwards nab-paclitaxel is the optimal alternative versus conventional paclitaxel.

\section{Results \\ State-transition model}

For both taxanes chemotherapy ends after the first year (ie, 18 cycles). The analysis of questionnaires highlights that chemotherapy cycles are usually administered in DH (80\%), followed by ambulatory (14\%), and inpatient (6\%) settings.

The proportion of responders is significantly higher for nab-paclitaxel (0.40) when compared to conventional paclitaxel (0.23; RR: 1.75 ; 95\% CI: 1.30-3.87). Median PFS is 0.52 and 0.40 years (ie, 6.2 months and 4.8 months) for nab-paclitaxel and conventional paclitaxel, respectively. TTP is significantly longer for nab-paclitaxel (HR: 0.72; 95\% CI: 0.55-0.94). Median OS is significantly longer for nab-paclitaxel (1.27 years versus 1.04 years; HR: 0.73; 95\% CI: 0.56-0.96).

For the sake of brevity, only AEs that differ significantly between nab-paclitaxel and conventional paclitaxel are reported (Table 3). Nab-paclitaxel outperforms conventional paclitaxel in reducing the incidence of neutropenia (OR: 1.95; 95\% CI: 1.33-2.87), whereas conventional paclitaxel performs better than nab-paclitaxel in limiting nausea (OR: 0.12; 95\% CI: 0.02-0.99), nervous system impairments (OR: 0.21; 95\% CI: 0.09-0.53), pain (including arthralgia; OR: 0.38; 95\% CI: 0.20-0.73), asthenia (OR: 0.35; 95\% CI: 0.15-0.86), and myalgia (OR: 0.23; 95\% CI: 0.07-0.68).

Table 3 Comparison of grade 3 and 4 adverse events: odds ratios and risk differences

\begin{tabular}{llll}
\hline Adverse event & Parameter & $\begin{array}{l}\text { Point } \\
\text { estimate }\end{array}$ & 95\% Cl \\
\hline Neutropenia & OR & 1.95 & $1.33-2.87$ \\
Febrile neutropenia & OR & 0.50 & $0.09-2.78$ \\
Infection & OR & 0.64 & $0.24-1.67$ \\
Anemia & OR & 0.51 & $0.05-5.63$ \\
Diarrhea & OR & 3.08 & $0.32-29.85$ \\
Nausea & OR & 0.12 & $0.02-0.99$ \\
Nervous system & OR & 0.21 & $0.09-0.53$ \\
Pain (included arthralgia) & OR & 0.38 & $0.20-0.73$ \\
Asthenia & OR & 0.35 & $0.15-0.86$ \\
Myalgia & OR & 0.23 & $0.07-0.68$ \\
Vomiting & RD & 0.03 & $-0.003-0.06$ \\
Stomatitis & RD & 0.01 & $-0.01-0.03$ \\
\hline
\end{tabular}

Notes: a OR > I or RD < 0 favor nab-paclitaxel; bif $95 \% \mathrm{Cl}$ does not include I (0), $O R(R D)$ is statistically significant.

Abbreviations: $\mathrm{Cl}$, confidence interval; $\mathrm{OR}$, odds ratio; $\mathrm{RD}$, risk difference. 
Table 4 Mean 5-year costs and cost-effectiveness analysis (€20II)

\begin{tabular}{|c|c|c|c|}
\hline Cost item & Nab-paclitaxel & Conventional paclitaxel (\%) & Difference $^{a}$ \\
\hline Chemotherapy & $5935(40.75)$ & $4170(34.58)$ & 1765 (70.42) \\
\hline $\begin{array}{l}\text { Chemotherapy administration, premedication, } \\
\text { and postmedication }\end{array}$ & $473(3.25)$ & $929(7.70)$ & $-455(-18.17)$ \\
\hline $\begin{array}{l}\text { Assessment and support: patients } \\
\text { receiving chemotherapy }\end{array}$ & II $37(7.81)$ & $1043(8.65)$ & $94(3.75)$ \\
\hline Assessment and support: patients off treatment & $766(5.26)$ & $485(4.02)$ & $28 I(11.23)$ \\
\hline Best supportive care following progression & 4921 (33.79) & $4139(34.33)$ & $782(31.20)$ \\
\hline End of life care & II53 (7.92) & $1168(9.68)$ & $-14(-0.58)$ \\
\hline Adverse events & $178(1.22)$ & $124(1.03)$ & $54(2.14)$ \\
\hline Total & $14,564(100.00)$ & $12,058(100.00)$ & $2506(100.00)$ \\
\hline QALYs $s^{b, c}$ & 0.805 & 0.640 & \\
\hline Incremental cost $(\Delta C)$ & 2506 & - & - \\
\hline Incremental QALYs ( $\triangle \mathrm{QALYs}$ ) & 0.165 & - & - \\
\hline ICER $(\Delta \mathrm{C} / \Delta \mathrm{QALYs})$ & $15,189^{d}$ & & \\
\hline
\end{tabular}

Notes: ${ }^{a}$ Cost of nab-paclitaxel - cost of conventional paclitaxel; brogression-free life years saved with nab-paclitaxel (conventional paclitaxel): $0.6 \mathrm{I} 5$ ( $\left.0.48 \mathrm{I}\right)$; clife years saved with nab-paclitaxel (conventional paclitaxel): I.439 (I.I73); ${ }^{9} 95 \%$ CI ICER: €II,89I-€28,4I5.

Abbreviations: QALYs, quality-adjusted life-years; ICER, incremental cost-effectiveness ratio; Cl, confidence interval.

\section{Resource consumption associated costs and cost-effectiveness analysis}

Mean 5-year cost for nab-paclitaxel and conventional paclitaxel reaches $€ 14,564$ and $€ 12,058$, respectively (Table 4). For both nab-paclitaxel and conventional paclitaxel, the cost driver is chemotherapy $(40.75 \%$ and $34.58 \%$ of the mean 5 -year cost, respectively), whereas AE management accounts for the least relevant share of costs $(1.22 \%$ and $1.03 \%$ of the mean 5-year cost, respectively).

The sum of cost for premedication, chemotherapy administration, patients' surveillance, and postmedication is $49 \%$ lower for nab-paclitaxel (€473; range: €287-€924 versus $€ 929$; range: $€ 319-€ 1564$, respectively). This finding is mainly driven by the shorter mean time for chemotherapy administration and patients' surveillance that favors nab-paclitaxel $(70.00 \pm 17.80$ minutes versus $169.40 \pm 76.92$ minutes).

Focusing on the mean infusion time only, the difference in favor of nab-paclitaxel $(27.50 \pm 5.00$ minutes versus $105.00 \pm 70.36$ minutes) is even more noteworthy. In addition, four out of five oncologists reported no need for premedication for nab-paclitaxel, whereas premedication was deemed necessary for all patients on conventional paclitaxel.

Costs for the assessment and support of patients receiving and off chemotherapy were higher for nab-paclitaxel. This finding is highly related to the longer TTP associated with nab-paclitaxel treatment. Nab-paclitaxel reports higher cost for best supportive care following progression, but lower cost for end of life care. Those two findings are related to the longer OS for nab-paclitaxel patients even after they have progressed.
As expected, most of the costs are accrued during the first year of the Markov model for both nab-paclitaxel (€10,393, or $71 \%$ of the mean 5 -year cost) and conventional paclitaxel (€9125, or $76 \%$ of the mean 5-year cost).

When compared to conventional paclitaxel, the mean 5-year cost is $€ 2506$ higher for nab-paclitaxel (Table 4). Nab-paclitaxel is also more effective than conventional paclitaxel. During the 5-year period, nab-paclitaxel gains an extra 0.134 progression-free life years $(0.615$ versus 0.481$)$ and saves 0.265 life years more than conventional paclitaxel (1.439 versus 1.173 ). When expected survival is weighted for utility, this results in 0.165 incremental QALYs for nabpaclitaxel $(0.805$ versus 0.640$)$.

ICER indicates that each QALY gained with nab-paclitaxel would cost the INHS $€ 15,189$ (95\% CI: $€ 11,891-€ 28,415$ ).

\section{Sensitivity analyses}

Sensitivity analyses confirm the robustness of the base case findings.

One-way sensitivity analysis underscores that ICER is sensitive to variations in the cost of nab-paclitaxel and conventional paclitaxel (Table 5). Conversely, replacing the base case estimate of the main clinical results with the $95 \%$ CI limits as well as reductions in the DRG $410 \mathrm{DH}$ tariff have a negligible effect on ICER amount. Interestingly, the ICER remains stable and never exceeds $€ 18,787$, regardless of the hypotheses tested through one-way sensitivity analysis.

As expected, the Markov model time horizon plays a relevant role in determining the ICER amount. The difference between a 1- and 2-year span of time is quite remarkable, 
Table 5 One-way sensitivity analysis (cost in €20II)

\begin{tabular}{|c|c|c|c|}
\hline & LL 95\% Cl & ICER & UL 95\% Cl \\
\hline Base-case analysis & & 15,189 & \\
\hline \multicolumn{4}{|l|}{ Sensitivity analysis } \\
\hline $\begin{array}{l}\text { RR for response - nab-paclitaxel versus } \\
\text { conventional paclitaxel }\end{array}$ & 15,766 & & 14,356 \\
\hline $\begin{array}{l}\text { HR for TTP - nab-paclitaxel versus } \\
\text { conventional paclitaxel }\end{array}$ & 14,737 & & $|5,79|$ \\
\hline \multirow{2}{*}{$\begin{array}{l}\text { HR for OS - nab-paclitaxel versus } \\
\text { conventional paclitaxel }\end{array}$} & 14,833 & & 15,719 \\
\hline & $-10 \%$ base case parameter & & $+10 \%$ base case parameter \\
\hline $\begin{array}{l}\text { Cost of chemotherapy - conventional } \\
\text { paclitaxel }\end{array}$ & 17,717 & & $|2,66|$ \\
\hline Cost of chemotherapy - nab-paclitaxel & $|1,59|$ & & 18,787 \\
\hline Cost of anemia & $|5| 8 \mid$, & & 15,197 \\
\hline Cost of myalgia & 15,188 & & 15,190 \\
\hline Utility stable disease & 15,184 & & 15,194 \\
\hline Utility progression & $|5,75|$ & & 14,666 \\
\hline Utility stable responder & 16,268 & & 14,244 \\
\hline Reduction in DRG $410 \mathrm{DH}$ tariff $=0 \%$ & & 12,615 & \\
\hline Reduction in DRG $410 \mathrm{DH}$ tariff $=80 \%$ & & 16,733 & \\
\hline Discount rate $=0 \%$ & & 15,119 & \\
\hline Discount rate $=5 \%$ & & 15,236 & \\
\hline Discount rate $=7 \%$ & & 15,283 & \\
\hline Discount rate $=10 \%$ & & 15,534 & \\
\hline
\end{tabular}

Abbreviations: ICER, incremental cost-effectiveness ratio; LL, lower limit; Cl, confidence interval; UL, upper limit; RR, relative risk; HR, hazard ratio; TTP, time to progression; OS, overall survival; DRG, diagnosis related group; DH, day hospital.

as the ICER in the first year is $53 \%$ higher than in the second year ( $€ 23,445$ versus $€ 15,369)$. Interestingly, as discussed later on, differences in ICER values flatten out as time horizon increases, and they substantially overlap from year 3 $(€ 15,085)$ to $5(€ 15,189)$.

Threshold analysis shows that ICER for nab-paclitaxel becomes higher than $€ 40,000$ only assuming that conventional paclitaxel is freely delivered to INHS facilities (Figure 1).
When contrasted against the lower and the upper limits (€25,000 and $€ 40,000$, respectively) of the acceptability range for ICER proposed by the Italian Health Economics Association (AIES), ${ }^{31}$ CEAC highlights that the probability for nab-paclitaxel to be cost-effective is 0.96 and 0.99 (Figure 2, Panel A).

In cost-effectiveness terms, the probability of making the wrong decision by recommending nab-paclitaxel instead of

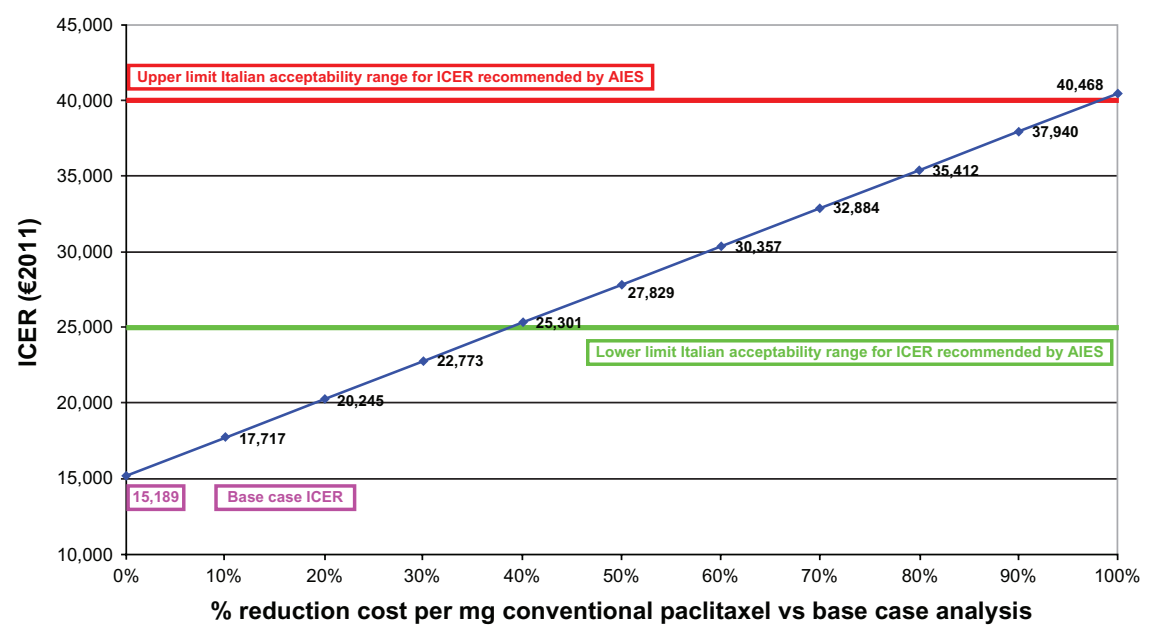

Figure I Threshold analysis for nab-paclitaxel.

Abbreviations: ICER, incremental cost-effectiveness ratio; AIES, Italian Health Economics Association. 

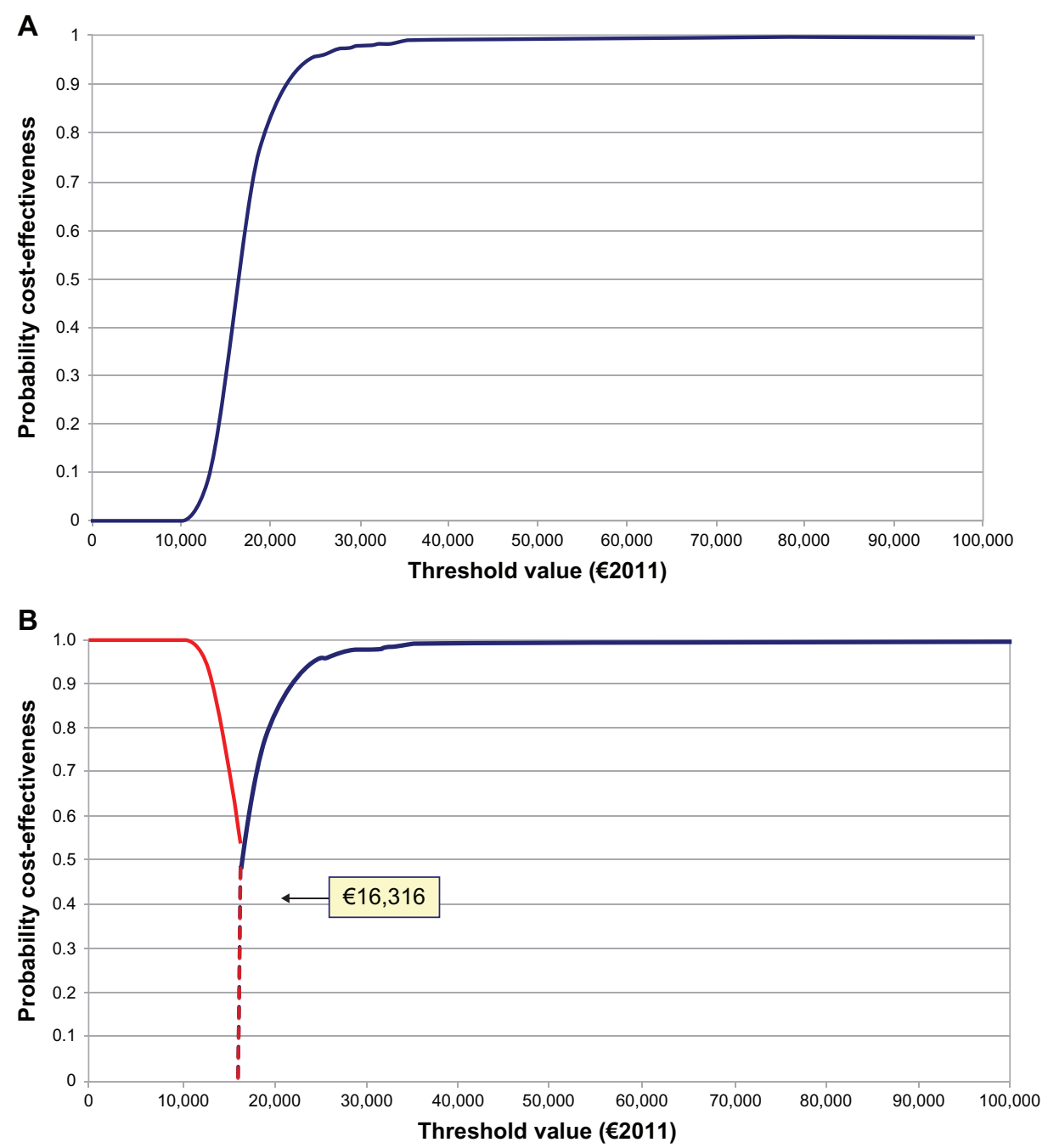

Figure 2 Probabilistic sensitivity analysis. (A) Cost-effectiveness acceptability curve for nab-paclitaxel. (B) Cost-effectiveness acceptability frontier. Note: Nab-paclitaxel is the optimal alternative from a threshold value of $€ 16,316$ onwards.

conventional paclitaxel is given by the complement of the probability of being cost-effective. In our study, it is worth noting that the probability of wrongly recommending nabpaclitaxel steeply decreases from 0.04 to 0.01 , moving along the bounds of the acceptability range for ICER proposed by AIES. Finally, CEAF reports nab-paclitaxel to be the optimal alternative from a threshold value of $€ 16,316$ onwards (Figure 2, Panel B).

\section{Discussion and conclusion}

We performed a Markov model supported cost-effectiveness analysis to compare costs and QALYs of nab-paclitaxel and conventional paclitaxel in MBC patients. As far as the cost side is concerned, the most relevant share of health care resources allocated to $\mathrm{MBC}$ treatment and related $\mathrm{AE}$ management were identified and quantified empirically from a convenience sample of five Italian reference centers for MBC treatment.
This economic evaluation has four main limitations. Firstly, due to the absence of patient level empirical comparative study covering a time span consistent with the assumed survival horizon for MBC patients, the Markov model extrapolated estimates for 5-year OS and PFS, as well as costs for both nab-paclitaxel and conventional paclitaxel from the results of a pivotal comparative trial. ${ }^{11}$ Despite the fact that this approach may cause our results to appear conditional on statistical technicalities and research hypotheses, modeling is commonly utilized in economic evaluation of health care programs when it comes to project costs and outcomes beyond the end of clinical trials. ${ }^{36,45}$ Besides, whenever long-term RCT results are lacking, it sounds wiser to support rationing in the health care sector with the available, although only partially empirical, evidence provided by models rather than relying on no guidance at all. ${ }^{46,47}$ 
The second limitation rests on the fact that utilities come from one UK source. However, utilities are usually more robust than cost data when applied to different national settings. ${ }^{15}$ Moreover, utility values played a quite negligible role in leading the results of the economic evaluation, as shown by one-way sensitivity analysis. Nevertheless, it would be interesting to elicit utility values from a sample of Italian MBC patients for a future cost-effectiveness analysis.

The third limitation concerns the assumption that AEs affect costs and QALYs for the first cycle of chemotherapy only. However, since no variation in the incidence of AEs during the following chemotherapy cycles is reported in the pivotal trial, ${ }^{11}$ and given that chemotherapy cycles end during the first year of the Markov model, this assumption does not impact on the ICER, since cost and outcomes occurring during the first year considered in an economic evaluation of health care programs are not discounted.

The last limitation relates to the fact that part of health care resource consumption was obtained from a convenience sample of five Italian oncological centers at the forefront in MBC treatment, which obviously differs from a random sample of health care facilities caring for MBC patients in Italy. ${ }^{21}$

Our results show that both the base case ICER and the related extremes of Monte Carlo 95\% CI fall below the bounds of the acceptability range per QALY gained (€25,000-€40,000), which was recently proposed by an AIES working group. ${ }^{31}$

Nab-paclitaxel is obviously cost-effective when ICER is contrasted against the most widely quoted threshold values for Europe $(€ 50,000)$ and the USA (US\$50,000). ${ }^{48,49}$ Moreover, for a threshold value higher than $€ 28,415$ (ie, the upper extreme of the $95 \% \mathrm{CI}$ for the base case ICER), INHS policymakers can be $95 \%$ confident that nab-paclitaxel is cost-effective when compared to conventional paclitaxel. ${ }^{44}$

It seems important to highlight that these findings are supported by better outcomes associated with nab-paclitaxel, both in terms of higher response, longer TTP, and longer OS, and in terms of a shorter time of administration. This last result favorably impacts on the costs of nab-paclitaxel.

A higher ICER of UK $£ 25,209$ at 2009 values ( $€ 28,817$, unadjusted for inflation ${ }^{50}$ for nab-paclitaxel was determined for the UK with a similar Markov model. ${ }^{13}$ However, quantitative comparisons between economic evaluations performed in different countries, even with roughly the same model of health care system (like Italy and the UK), should be handled very carefully, due, at minimum, to possible differences in unit costs for health care resource. ${ }^{44}$
According to CEAF, INHS decision makers should endorse nab-paclitaxel from a threshold value of $€ 16,316$ onwards. It is noteworthy that this threshold value is well below the lower limit of the AIES acceptability range. ${ }^{31}$ In addition, it is interesting for INHS decision makers that ICER dramatically decreases below $€ 20,000$ from year 2 onward. The time-dependent downward trend of the ICER seems to be fully explained by the fact that most of the costs, especially those related to chemotherapy that actually led to the 5-year mean cost for both nab-paclitaxel and conventional paclitaxel, had accrued during the first year of the Markov model. This also explains why base case ICER is not that sensitive to changes in discount rate, since costs (and QALYs) that occur during the first year are, in fact, left undiscounted. ${ }^{14,15}$

In conclusion, the findings of our research show that nab-paclitaxel is both more clinically effective (higher response, longer TTP, and longer OS), and cost-effective (affordable ICER for the INHS) than conventional paclitaxel in Italy.

\section{Acknowledgment}

Authors are extremely grateful to five anonymous referees for their helpful comments on an earlier draft of the manuscript.

\section{Disclosure}

The authors report no conflicts of interest with this work. This study was funded by the Health Economics and Outcomes Research Unit of Celgene Srl. However, the interpretation and reporting of the data are the sole responsibilities of the authors.

\section{References}

1. Grande E, Inghelmann R, Francisci S, et al. Regional estimates of breast cancer burden in Italy. Tumori. 2007;93(4):374-379.

2. Ferlay J, Shin HR, Bray F, Forman D, Mathers C, Parkin DM [homepage on the Internet]. Cancer incidence and mortality worldwide: IARC CancerBase No 10. Lyon: International Agency for Research on Cancer; 2010. Available from: http://globocan.iarc.fr/factsheets/populations/factsheets asp?uno=380\#WOMEN. Accessed September 13, 2011.

3. The National Institute for Health and Clinical Excellence (NICE). Advanced Breast Cancer: Diagnosis and Treatment - Evidence Review. (CG81). London: The National Institute for Health and Clinical Excellence; 2009. Available from: http://www.nice.org.uk/nicemedia/ live/11778/44046/44046.pdf. Accessed October 14, 2011.

4. National Comprehensive Cancer Network (NCCN) [homepage on the Internet]. Practice guidelines in oncology V2.2010: breast cancer. Available from: http://www.nccn.orgprofessionals/physician_gls/pdf/breast.pdf. Accessed October 14, 2011.

5. Gradishar WJ. Albumin-bound paclitaxel: a next-generation taxane. Expert Opin Pharmacother. 2006;7(8):1041-1053.

6. Desai NP, Trieu V, Hwang LY, Wu R, Soon-Shiong P, Gradishar WJ. Improved effectiveness of albumin-bound (nab) paclitaxel versus polysorbate-based docetaxel in multiple xenografts as a function of HER2 and SPARC status. Anticancer Drugs. 2008;19(9):899-909. 
7. Desai N, Trieu V, Damascelli B, Soon-Shiong P. SPARC expression correlates with tumor response to albumin-bound paclitaxel in head and neck cancer patients. Transl Oncol. 2009;2(2):59-64.

8. Weiss RB, Donehower RC, Wiernik PH, et al. Hypersensitivity reactions from taxol. J Clin Oncol. 1990;8(7):1263-1268.

9. ten Tije AJ, Verweij J, Loos WJ, Sparreboom A. Pharmacological effects of formulation vehicles: implications for cancer chemotherapy. Clin Pharmacokinet. 2003;42(7):665-685.

10. Gelderblom H, Verweij J, Nooter K, Sparreboom A. Cremophor EL: the drawbacks and advantages of vehicle selection for drug formulation. Eur J Cancer. 2001;37(13):1590-1598.

11. Gradishar WJ, Tjulandin S, Davidson N, et al. Phase III trial of nanoparticle albumin-bound paclitaxel compared with polyethylated castor oil-based paclitaxel in women with breast cancer. J Clin Oncol. 2005;23(31):7794-7803.

12. European Medicines Agency (EMA). Abraxane (paclitaxel) [homepage on the Internet]. London: European Medicines Agency; 2009. Available from: http://www.ema.europa.eu/ema/index.jsp?curl=pages/medicines/ human/medicines/000778/human_med_000620.jsp\&murl=menus/

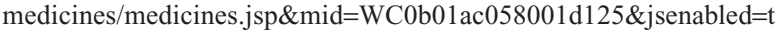
rue\#product-info/. Accessed October 14, 2011.

13. McLeod E, Samyshkin Y, Lloyd A, Prunieras F, Canney P. A UK costeffectiveness analysis of paclitaxel albumin compared to solvent-based paclitaxel monotherapy and docetaxel monotherapy for pretreated metastatic breast cancer (MBC). Proceedings of the International Society for Pharmacoeconomics and Outcomes Research (ISPOR) 13th Annual European Congress; November 6-9, 2010; Prague, Czech Republic.

14. Gold MR, Siegel JE, Russel LB, Weinstein MC, editors. Cost-effectiveness in Health and Medicine. New York: Oxford University Press; 1996.

15. Drummond MF, Schulper MJ, Torrance GW, O’Brien BJ, Stoddart GL. Methods for the Economic Evaluation of Health Care Programmes, 3rd ed. Oxford: Oxford University Press; 2005.

16. European Medicines Agency (EMA). Abraxane. Summary of Product Characteristics. London: European Medicines Agency. Available from: http://www.ema.europa.eu/docs/en_GB/document_library/ EPAR_-_Product_Information/human/000778/WC500020435.pdf

17. Sonnenberg FA, Beck JR. Markov models in medical decision making: a practical guide. Med Decis Making. 1993;13(4):322-338.

18. All Wales Medicines Strategy Group. Final Appraisal Report. Paclitaxel albumin $\left(\right.$ Abraxane $\left.^{\circledR}\right)$. Abraxis BioScience Limited. Advice No: 0410 - April 2010; 2010. Available from: http://www.wales.nhs. uk/sites3/docopen.cfm?orgid=371\&ID=158203\&968E7C18-E3ADFBDF-0929282839779CBA. Accessed October 14, 2011.

19. Scottish Medicines Consortium (SMC). Paclitaxel Albumin Powder for Suspension for Infusion (Contains $100 \mathrm{mg}$ Paclitaxel as Paclitaxel Albumin) (Abraxane ${ }^{\circledR}$ ) No (556/09). Abraxis BioScience Limited; 2010. Available from: http://www.scottishmedicines.org.uk/files/advice/ paclitaxel_Abraxane_FINAL_March_2010_amended_For_Website. pdf. Accessed October 15, 2011.

20. Cooper NJ, Abrams K, Sutton AJ, Turner D, Lambert PC. A Bayesian approach to Markov modelling in cost-effectiveness analyses: application to taxane use in advanced breast cancer. J R Stat Soc Ser A Stat Soc. 2003;166(3):389-405.

21. Lohr SL. Sampling: Design and Analysis, 2nd ed. Boston: Brooks/ Cole; 2010.

22. Ministero della Salute. Dipartimento Della Qualita'. Direzione Generale Della Programmazione Sanitaria, Dei Livelli Di Assistenza E Dei Principi Etici Di Sistema. Commissione nazionale per la definizione e l'aggiornamento dei Livelli essenziali di assistenza. Nuova caratterizzazione dell'assistenza territoriale domiciliare e degli interventi ospedalieri a domicilio. Roma: Febbraio 24, 2007. Italian.

23. Gazzetta Ufficiale Repubblica Italiana. Serie generale, n. 295 del 20/12/2006:31. Italian.

24. Gazzetta Ufficiale Repubblica Italiana. Serie generale, n. 241 del 14/10/2010:52. Italian.

25. Dialogo sui farmaci. Prontuario Commentato 2010. Verona: Dialogo sui farmaci srl, 2010. Italian.
26. Momento Medico. Farmabank 2011. Salerno: Momento Medico s.r.1., 2011. Italian.

27. Gerzeli S, Aguzzi G. Consumo di risorse e costi nei pazienti con carcinoma alla mammella metastatizzato HER2+. Italian Journal of Public Health. 2009;6(1 Suppl 1):S20-S30. Italian.

28. Ministero della Sanità. Decreto ministeriale n. 150 del 22 Luglio 1996. Prestazioni di assistenza specialistica ambulatoriale erogabili nell'ambito del Servizio sanitario nazionale e relative tariffe. Supplemento ordinario alla Gazzetta Ufficiale n. 216 del Settembre 14, 1996 Serie generale. Roma: Istituto Poligrafico e Zecca dello Stato, 1996. Italian.

29. Conferenza Permanente per i Rapporti tra lo Stato le Regioni e le Province Autonome di Trento e Bolzano. Tariffa Unica Convenzionale per le prestazioni di assistenza ospedaliera. Regole e tariffe valide per l'anno 2008. Conferenza Permanente per i Rapporti tra lo Stato le Regioni e le Province Autonome di Trento e Bolzano. Roma: Conferenza Permanente per i Rapporti tra lo Stato le Regioni e le Province Autonome di Trento e Bolzano, Luglio 2009. Italian.

30. Regione Campania - Giunta Regionale - Seduta del 28 luglio 2006 Deliberazione N. 1034 - Area Generale di Coordinamento - N. 19 - Piano Sanitario Regionale e Rapporti con le UU.SS.LL. - N. 20 - Assistenza-Sanitaria - Farmaci oncologici ad alto costo: rendicontazione tramite il file F. Napoli: Bollettino Ufficiale della Regione Campania, n. 40, settembre 4, 2006. Italian.

31. Fattore $\mathrm{G}$ per Gruppo di lavoro Associazione Italiana di Economia Sanitaria (AIES). Proposta di linee guida per la valutazione economica degli interventi sanitari in Italia [A proposal for guidelines for the economic evaluation of health interventions in Italy]. Pharmacoeconomics Italian Research Articles. 2009;11(2):83-93. Italian.

32. Gardner MJ, Altman DG. Confidence intervals rather than $P$ values: estimation rather than hypothesis testing. Br Med J (Clin Res Ed). 1986;292(6522):746-750.

33. Briggs AH. Handling uncertainty in economic evaluation. In: Drummond M, McGuire A, editors. Economic Evaluation in Health Care: Merging Theory with Practice. Oxford: Oxford University Press; 2001:172-214.

34. Capri S, Morabito A, Carillio C, et al. Valutazione economica di erlotinib, docetaxel e pemetrexed nel trattamento di seconda linea del carcinoma polmonare non a piccole cellule [Economic evaluation of erlotinib, docetaxel and pemetrexed as second line therapy in non-small cell lung cancer]. Pharmacoeconomics - Italian Research Articles. 2007;9(2):113-124. Italian.

35. Briggs A, Fenn P. Confidence intervals or surfaces? Uncertainty on the cost-effectiveness plane. Health Econ. 1998;7(8):723-740.

36. Briggs A, Schulper M, Claxton K. Decision Modelling for Health Economic Evaluation. Oxford: Oxford University Press; 2006.

37. Efron B, Tibshirani RJ. An Introduction to the Bootstrap. New York: Chapman and Hall; 1993.

38. Briggs AH, O'Brien BJ, Blackhouse G. Thinking outside the box: recent advances in the analysis and presentation of uncertainty in costeffectiveness studies. Annu Rev Public Health. 2002;23:377-401.

39. Willan AR, Briggs AH. Statistical Analysis of Cost-Effectiveness Data. Chichester: Wiley; 2006:51-57.

40. O'Hagan A, Stevens JW. The probability of cost-effectiveness. BMC Med Res Methodol. 2002;2:5.

41. FenwickE, Claxton K, Sculpher M. Representing uncertainty: the role of costeffectiveness acceptability curves. Health Econ. 2001;10(8):779-787.

42. Spiegelhalter DJ, Abrams KR, Myles JP. Bayesian Approach to Clinical Trials and Health-Care Evaluation. Chichester: Wiley; 2004.

43. Stinnett AA, Mullahy J. Net health benefits: a new framework for the analysis of uncertainty in cost-effectiveness analysis. Med Decis Making. 1998;18(Suppl 2):S68-S80.

44. Glick HA, Doshi JA, Sonnad SA, Polsky D. Economic Evaluation in Clinical Trials. Oxford: Oxford University Press; 2007.

45. Briggs A, Mihaylova B, Sculpher M, et al; for EUROPA Trial Investigators. Cost effectiveness of perindopril in reducing cardiovascular events in patients with stable coronary artery disease using data from the EUROPA study. Heart. 2007;93(9):1081-1086. 
46. Weinstein MC, O’Brien B, Hornberger J, et al; for SPOR Task Force on Good Research Practices - Modeling Studies. Principles of good practice for decision analytic modeling in health-care evaluation: report of the ISPOR Task Force on Good Research Practices - Modeling Studies. Value Health. 2003;6(1):9-17.

47. Ades AE, Sculpher M, Sutton A, et al. Bayesian methods for evidence synthesis in cost-effectiveness analysis. Pharmacoeconomics. 2006;24(1):1-19.

48. Jönsson B. Changing health environment: the challenge to demonstrate cost-effectiveness of new compounds. Pharmacoeconomics. 2004; 22 Suppl 4:5-10.
49. Mark DB, Hlatky MA, Califf RM, et al. Cost-effectiveness of thrombolytic therapy with tissue plasminogen activator as compared with streptokinase for acute myocardial infarction. N Engl J Med. 1995;332(21): 1418-1424.

50. Ufficio Italiano Cambi. Cambi giornalieri. Quotazioni in Euro [homepage on the Internet]. Available from: http://cambi.bancaditalia. it/cambi/cambi.do?lingua=it\&to=cambiGForm. Accessed October 14, 2011. Italian.

\section{Publish your work in this journal}

ClinicoEconomics \& Outcomes Research is an international, peerreviewed open-access journal focusing on Health Technology Assessment, Pharmacoeconomics and Outcomes Research in the areas of diagnosis, medical devices, and clinical, surgical and pharmacological intervention. The economic impact of health policy and health systems

Submit your manuscript here: http://www.dovepress.com/clinicoeconomics-and-outcomes-research-journal organization also constitute important areas of coverage. The manuscript management system is completely online and includes a very quick and fair peer-review system, which is all easy to use. Visit http://www.dovepress.com/testimonials.php to read real quotes from published authors. 